\title{
SITE AMPLIFICATION ESTIMATES IN THE GARIGLIANO \\ VALLEY, CENTRAL ITALY, BASED ON DENSE ARRAY MEASUREMENTS OF AMBIENT NOISE
}

\author{
By L. Malagnini, A. Rovelli, S. E. Hough, L. Seeber
}

\begin{abstract}
A frequency-domain formulation of the Aki $(1957,1965)$ autocorrelation method has been applied to seismic noise recorded by a 100-m wide circular array deployed on soft Holocene sediments in the Garigliano river valley, where a large amplification of ground motion during earthquakes was experienced (Rovelli et al., 1988). The application of this method to ambient noise recordings demonstrates that microtremors in the valley are dispersive and dominated by surface waves. By assuming that the vertical component reflects Rayleigh wave motion, we obtain a dispersion curve that is interpreted in terms of a layered shear-wave velocity structure. Layer thicknesses are constrained by the stratigraphic information provided by a deep hole drilled in the area, and shear velocities are estimated by means of a trial-and-error approach to achieve a satisfactory fit of the ambient noise dispersion. The best-fit velocity model is used to compute a theoretical transfer function, which is then compared with an average spectral ratio obtained from earthquake weak ground motions recorded at two stations, one in the valley and the other on a limestone reference site. An overall agreement is found between the theoretical curve and the observed spectral ratios. The discrepancies that do exist may be ascribed to the assumption of 1-D inhomogeneity which considerably simplifies the theoretical transfer function.

Our results show that the spatial-correlation method can be useful to infer velocity structure down to depths of hundreds of meters, when generalized geological informations are available, and can thus provide useful constraints for theoretical methodologies for the prediction of site response.
\end{abstract}

\section{INTRODUCTION}

Ambient noise analyses have been used by many authors to infer potential earthquake response at sediment sites (e.g., Ohta et al., 1978; Lermo et al., 1988; Field et al., 1990). In some investigations the ambient noise spectrum is observed to have a sharp peak that can be modeled as a fundamental resonance frequency of a sediment layer (Field et al., 1990, Hough et al., 1992). Spectral peaks near 2 to $3 \mathrm{~Hz}$ are observed at most sites on Holocene sediments within the Tiber Valley (Hough et al., 1992), including the city of Rome. These peaks may represent the fundamental resonance frequency of the Holocene sediment layer.

Nevertheless, predictions of spectral properties of site response based solely on ambient noise analyses remain controversial and limitations of the method have been discussed in several papers (e.g., Udwadia and Trifunac, 1973; Rovelli

${ }^{*}$ Present address of S. E. Hough. United States Geological Survey, 5250 South Wilson Avenue, Pasadena, California 91106. 

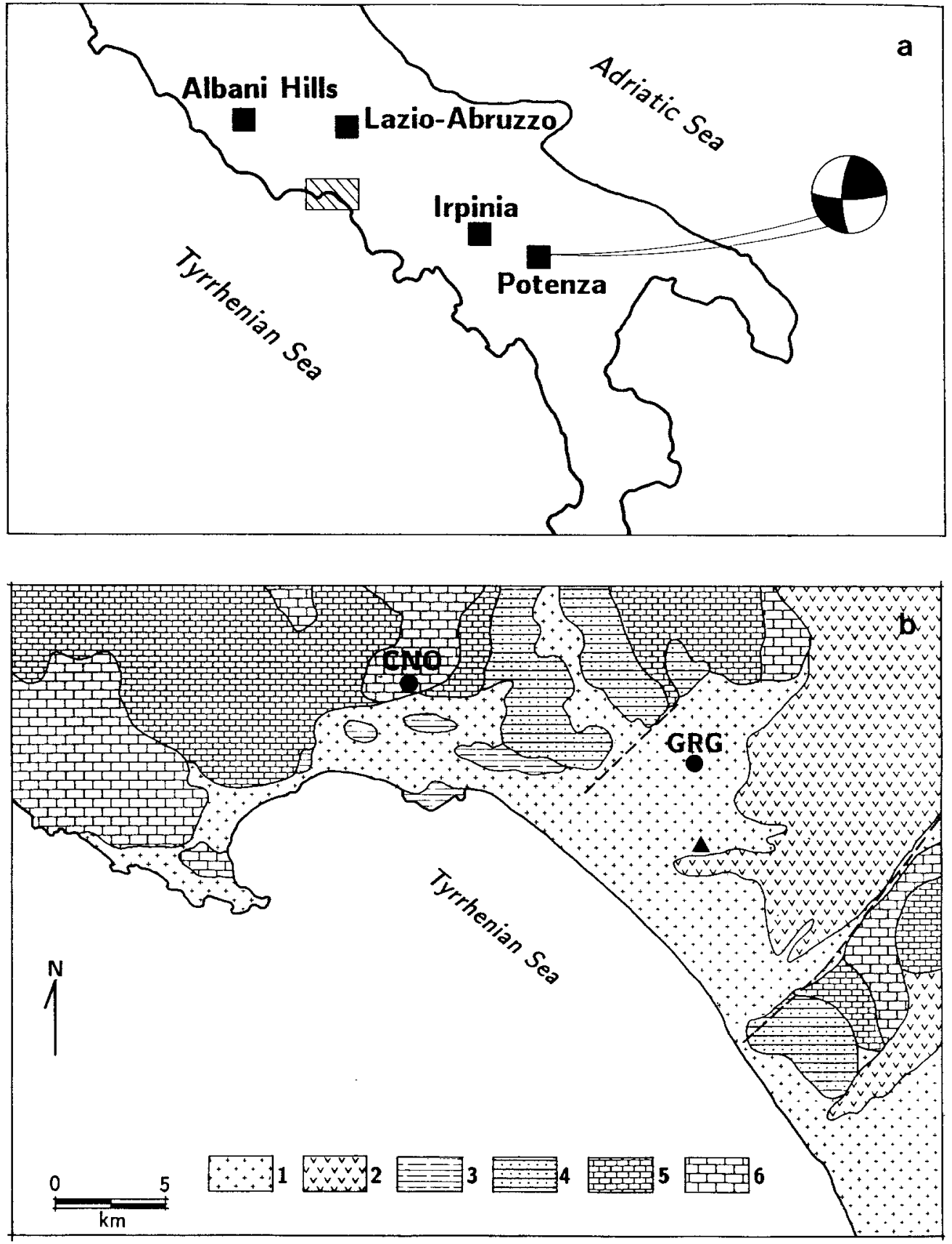

Fig. 1. (a) Map of central-southern Italy, showing the epicenters (solid squares) of seismic events recorded in the Garigliano Valley (shaded rectangle). (b) The shaded rectangle in (a) is enlarged showing the geological map of the Garigliano Valley. The positions of two recording stations (GRG and $\mathrm{CNO}$ ) are indicated by solid circles. A dense array was deployed close to GRG to record ambient noise. Dashed lines traced on the map indicate the positions of the normal faults that characterize the graben-like geometry of the valley. (1, Holocene and Pleistocene sediments; 2, volcanic products; 3, Pliocene breccias; 4, Miocene marly limestones; 5 , Cretaceous limestones; 6 , Jurassic limestones). The Potenza earthquake focal mechanism is by Goran Ekström (personal comm.). 
et al., 1991; Gutierrez and Singh, 1992). Before the ambient noise method can be applied with confidence, it is necessary to address several outstanding questions concerning the nature of the ambient noise wavefield. One of these questions was addressed by Aki (1957), who suggested that ambient noise is dominated by surface waves that are generated as incident body-wave noise impinges on the sediment-basement interface. From array observations at sites near Tokyo, he concluded that ambient noise is dominated by Love waves. Other questions concerning the nature of the ambient noise wavefield include: (1) if ambient noise does consist of a random superposition of dispersive surface waves, then how is the persistent single dominant period maintained, and (2) what is the relationship between this period and the predicted body-wave resonance frequency?

The stochastic analysis proposed by Aki (1957) may be a suitable approach to study ambient noise, if this noise can be assumed to be random in nature. The velocity structure of sites has been inferred by Aki (1965) and Ferrazzini et al. (1991) from the spatial correlation analysis of ambient noise. The aim of the present study is to address some of the questions regarding the role of ambient noise measurements in investigating site response. We analyze noise measurements from a dense 2-D array in the Garigliano river valley, approximately 100 $\mathrm{km}$ southeast of the city of Rome (Fig. 1).

\section{DATA}

We deployed a circular array of four stations in the Garigliano river valley. Three stations were installed at the vertices of an equilateral triangle inscribed in a circle, and one in the center. The circle radius was $50 \mathrm{~m}$. Each array site was instrumented with a three-component Mark-3-D 1-sec sensor and a digital Lennartz Mars- 88 recorder. These sensors were placed in small $(0.5 \mathrm{~m}$ by $0.5 \mathrm{~m})$ holes dug into soil. The sampling rate was $250 \mathrm{sps}$, and noise was recorded over 10-min windows. Accurate timing was obtained by synchronizing each site to a radio time signal (DCF77) before recording.

Ambient noise within the valley is high; absolute amplitudes of $10^{-5}-10^{-4}$ $\mathrm{mm} / \mathrm{sec}$ are typically observed. Figure $2 \mathrm{a}$ shows typical 20 -sec traces from one of the array stations. Using a 10-min recording of noise, we compute the spectra for 10 nonoverlapping 20 -sec windows. Spectra of both vertical and horizontal motion are then averaged to yield the results shown in Figures $2 \mathrm{~b}$ and $2 \mathrm{c}$, respectively. The spectrum of horizontal motion is obtained from the square root of the sum of the squares of the spectra of the two horizontal components of motion. The spectrum of noise shows a sharp peak on the horizontal component at $1.3 \mathrm{~Hz}$, approximately. The vertical component shows lower amplitudes, suggesting that the energy is mainly horizontal.

\section{ANALYSIS OF ARRAy DATA}

Aki $(1957,1965)$ demonstrated that phase velocities can be determined for sediment layers using a statistical analysis of ambient noise. Assuming that microtremors represent the sum of horizontally-propagating waves that travel with the same phase velocity for a given frequency, and that waves propagating in different directions are statistically independent, the phase velocity can be related to an azimuthal average of the spatial correlation. Aki (1957) shows that 

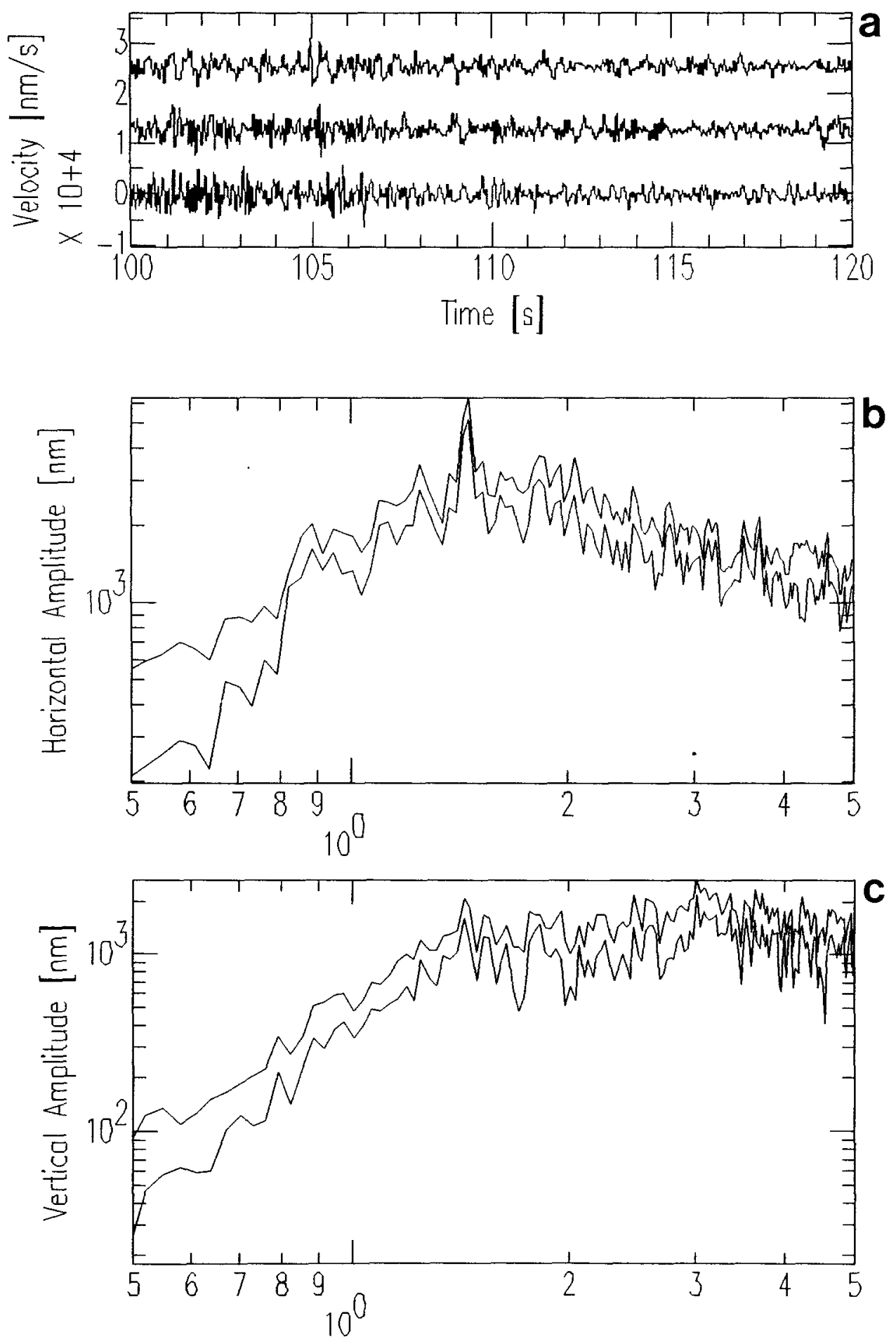

Frequency $[\mathrm{Hz}]$

Fig. 2. (a) 20-sec traces from three-component recordings at one of the array stations. (b) Averaged spectrum of the horizontal component of ambient noise calculated over ten 20-sec nonoverlapping windows. The two curves represent average $\pm 1 \sigma$. (c) The same in (b), calculated over the vertical component of motion. 
given a circular array of stations with a station in the center, a space correlation function $\phi(r, \lambda)$ can be defined as

$$
\phi(r, \lambda)=\langle u(x, y, t) \cdot u(x+r \cos \lambda, y+r \sin \lambda, t)\rangle,
$$

where $u(x, y, t)$ is the waveform (velocity) observed at point $(x, y)$ at time $t, r$ is the radius of the circular array, $\lambda$ is the azimuth, and $\langle\cdot\rangle$ denotes the ensemble average. An azimuthal average of this function is given by

$$
\phi(r)=\frac{1}{\pi} \int_{0}^{\pi} \phi(r, \lambda) d \lambda .
$$

The power spectrum $\Phi(\omega)$ can be related to $\phi(r)$ via the zeroth order Hankel transform (Aki, 1957):

$$
\phi(r)=\frac{1}{\pi} \int_{0}^{\infty} \Phi(\omega) J_{0}\left(\frac{\omega r}{c(\omega)}\right) d \omega
$$

where $\omega$ is the angular frequency and $J_{0}(\omega r / c(\omega))$ is the zeroth order Bessel function; $c(\omega)$ is the frequency-dependent phase velocity. If noise recordings from the array are bandpass filtered over a narrow frequency band centered on $\omega_{0}$ and $\phi(r)$ is computed for the filtered series, then the (normalized to the power spectrum) spatial correlation function will be of the form (Aki, 1957):

$$
\phi\left(r, \omega_{0}\right)=J_{0}\left(\frac{\omega_{0} r}{c\left(\omega_{0}\right)}\right) .
$$

Thus, Aki (1957) yields phase velocities from the correlation function computed for unimodal waves statistically independent in space and time. Although we have noted that the noise amplitudes seem to be higher on the horizontal components of motion, significant "signal" is present on the vertical component as well. Because any energy on the vertical component can be assumed to result from Rayleigh waves (if ambient noise does indeed consist of surface waves), the dispersion obtained from the vertical component is more easily interpreted than dispersion from horizontal component. We therefore apply the above formulas to the vertical component of motion recorded by the circular array. Assuming that ambient noise is comprised mainly of surface waves (e.g., Aki, 1957; Ferrazzini et al., 1991), the results from applications of equations (1) to (4) to the vertical component of the ground motion can be interpreted as Rayleigh wave phase velocities.

Equation (4) can be applied to averaged correlation functions calculated for a set of narrow frequency bands between 0.5 and $5 \mathrm{~Hz}$. In this study, however, we apply an alternative, frequency-domain formulation of the method. From the 
correlation theorem (e.g., Bracewell, 1978) it follows that

$$
\begin{aligned}
& \phi\left(r, \omega_{0}, \lambda\right)= \\
& \frac{2 \int_{\omega_{0}-\delta \omega}^{\omega_{0}+\delta \omega} \operatorname{Re}\left[U(\omega, x, y) U^{*}(\omega, x+r \cos \lambda, y+r \sin \lambda)\right] d \omega}{\left(2 \int_{\omega_{0}-\delta \omega}^{\omega_{0}+\delta \omega} U^{2}(\omega, x, y) d \omega 2 \int_{\omega_{0}-\delta \omega}^{\omega_{0}+\delta \omega} U^{2}(\omega, x+r \cos \lambda, y+r \sin \lambda) d \omega\right)^{1 / 2}}
\end{aligned}
$$

where $\phi\left(r, \omega_{0}, \lambda\right)$ is the correlation computed at frequency $\omega_{0}$ between two noise recordings ( $x, y$ define the central station position); $\lambda$ is the azimuth of the peripheral stations with respect to the center of the array; $r$ is the radius of the array. $U(\omega, x, y)$ indicates the Fourier transform of $u(t, x, y)$ and $U^{*}(\omega, x$ $+r \cos \lambda, y+r \sin \lambda)$ is the complex conjugate of the Fourier transform of $u(t, x+r \cos \lambda, y+r \sin \lambda)$ (see equation (1)). The symbol $\operatorname{Re}[\ldots]$ indicates the real part of the complex quantity in squared brackets. The factors 2 that appear in equation (5) are due to symmetry reasons.

Equation (5) is used to compute $\phi\left(r, \omega_{0}\right)$, i.e., the azimuthal average of the correlation function (Henstridge, 1979). The calculation of $\phi\left(r, \omega_{0}\right)$ has been performed for five contiguous 1-min windows, between 0.5 and $8 \mathrm{~Hz}$; the results are averaged to obtain the final results shown in Figure 3a. Using equation (4), the inferred correlation function can be used to estimate phase velocities between 0.5 and $8 \mathrm{~Hz}$ (Fig. 3b). The error bounds in Figure $3 \mathrm{~b}$ indicate $\pm 1 \sigma$ uncertainties, as computed from five individual windows. This figure shows that the waves comprizing the ambient noise are dispersive. Assuming the vertical components reflect Rayleigh wave motion, we can calculate a theoretical dispersion curve for a 1-D velocity profile using the method of Takeuchi and Saito (1972). To fit the observed dispersion we use a forward modeling approach. The starting model was based on gross stratigraphic information provided by a 2000-m deep hole drilled in the valley by the Italian Oil Company (AGIP), about $2 \mathrm{~km}$ from the array. A first interface between a soft sediment layer and the rest of the Holocene alluvium is included at $20 \mathrm{~m}$, evidence from this interface comes from holes drilled for a new freeway a few hundred meters from the Garigliano array. Figure $3 \mathrm{~b}$ suggests that high-frequency ( $>5 \mathrm{~Hz}$ ) propagation of surface waves is mainly controlled by this soft upper layer, whereas lower-frequency dispersion is controlled by deeper layers. Based on the assumption of unimodal propagation of ambient noise waves, we computed the amplitude of the theoretical eigenfunction of the fundamental mode as a function of depth and frequency. It emerges that the amplitudes at low frequencies $(\approx 1 \mathrm{~Hz})$ are significant up to $1000 \mathrm{~m}$ in depth. This means that only the upper three layers shown by the stratigraphy are strictly needed to describe the phase velocity data. However, we used the entire available stratigraphy up to $2000 \mathrm{~m}$. The use of additional deeper layers does not significantly change the theoretical dispersion curve, but may offer the advantage of a more realistic transfer function.

The calculated dispersion curve is satisfactorily matched by our theoretical computation based on the 5-layer model. Figure 4 shows the final velocity model, obtained through the trial-and-error procedure. Some cross-hole $P$ - and 

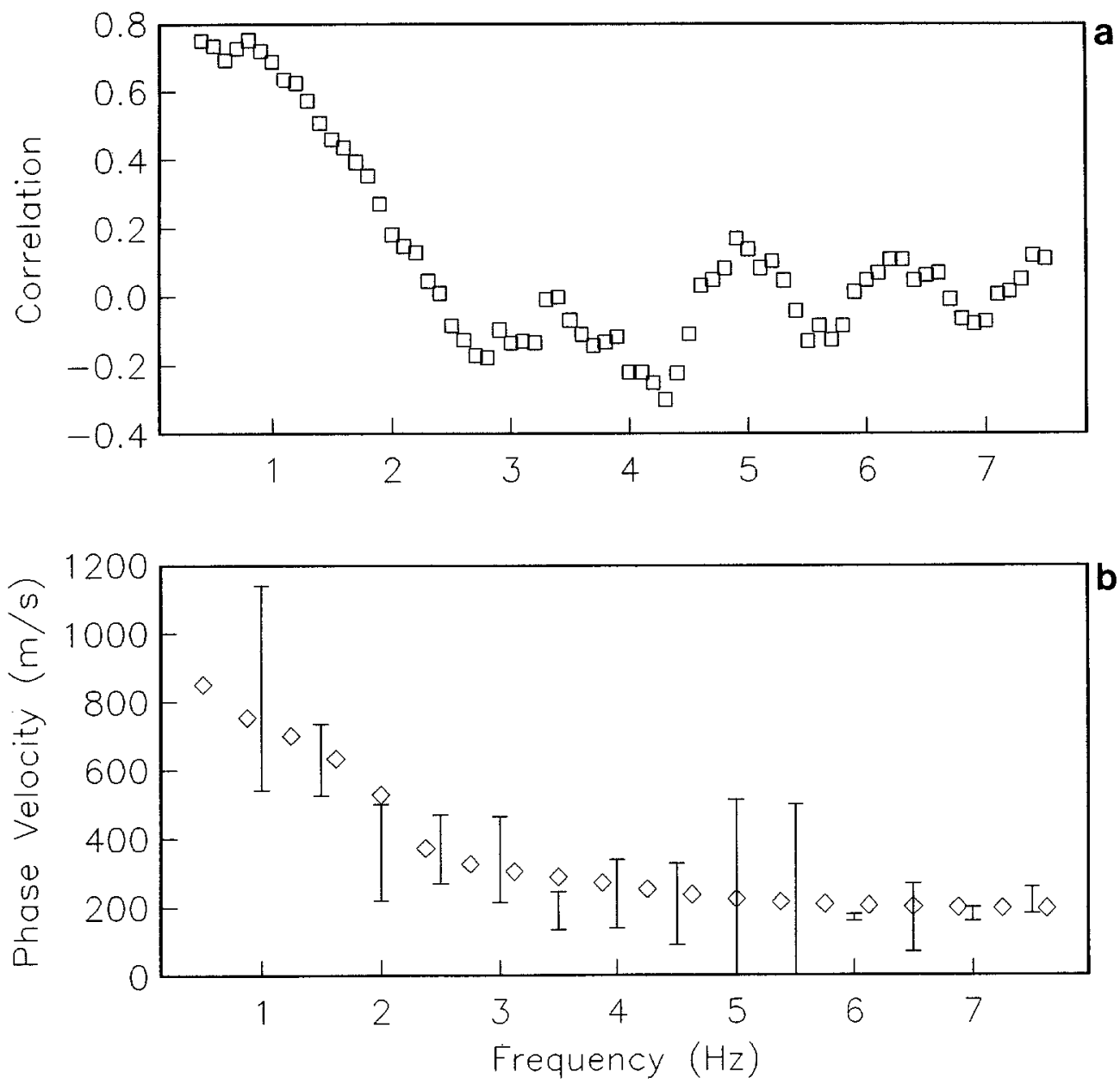

FiG. 3. (a) Correlation function $\phi(r, \omega)$, calculated averaging results obtained from 5 contiguous 1-min windows (squares). (b) The values shown in (a) are used to derive phase velocities in the frequency range 1 to $8 \mathrm{~Hz}$. The error bars in (b) correspond to $\pm 1 \sigma$ uncertainties. Rhombs show the theoretical Rayleigh wave dispersion obtained from the final velocity model (see Fig. 4).

$S$-wave velocity measurements up to $100 \mathrm{~m}$ in depth have been recently performed by the Italian Agency for Electric Power (ENEL). Our final model inferred from the dispersion analysis agrees with the measured velocity profile, with a misfit on velocities lower than $10 \%$ in the upper $90 \mathrm{~m}$ (ENEL, Direzione delle Costruzioni, unpublished report). Thus, when stratigraphic data are available, realistic velocity models can be obtained using the spatial autocorrelation method, as long as a 1-D approximation is valid.

\section{MODELING}

Our final velocity structure is used to produce a theoretical 1-D transfer function. The transfer function shown in Figure 5 (dashed line) is computed using the reflection-matrix technique of Kennett and Kerry (1979).

Two- and 3-D methods may be necessary to model surface-wave generation in sediment-filled valleys (e.g., Frankel et al., 1991), especially in narrow deep valleys (Bard and Bouchon, 1985) or in valleys with unusually sharp boundaries 


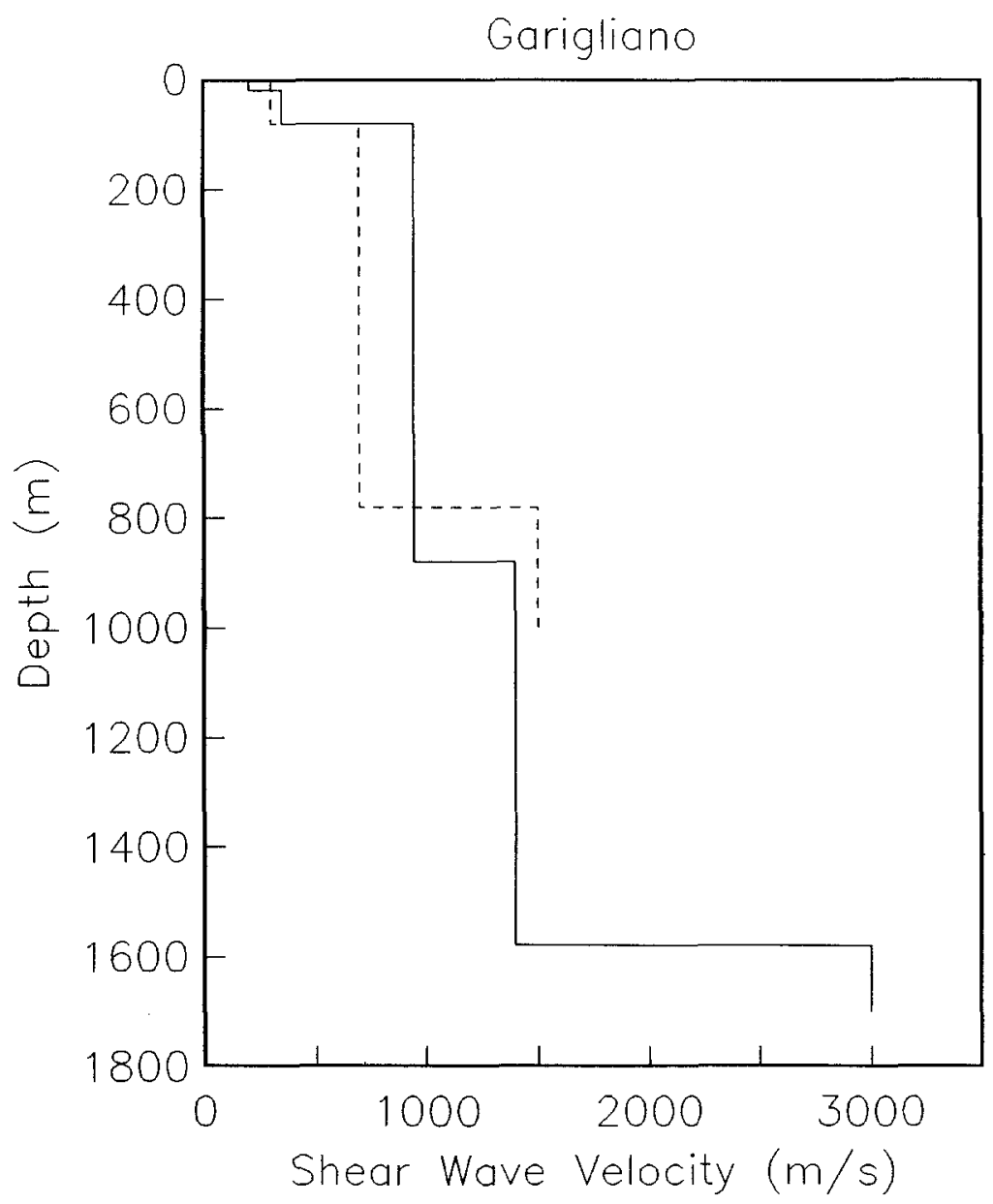

FrG. 4. The dashed line shows the initial velocity structure used to model the Rayleigh waves dispersion inferred from ambient noise at GRG. Velocity values were derived from a generalized geological assessment of the subsurface structure at GRG. The solid line shows the final model that fits the Rayleigh wave dispersion shown in Figure $3 \mathrm{~b}$. In the upper $90 \mathrm{~m}$, in situ velocity measurements show small differences $(<10 \%)$ compared to results from the inversion of the dispersion curve (ENEL, Direzione delle Costruzioni, unpublished report).

(Schuster et al., 1988). In broad, flat valleys, a 1-D response is predicted to dominate (Bard and Bouchon, 1985) and 1-D methods can be successful in predicting both the amplitude and the frequency content of observed transfer functions (e.g., Hough, 1990). The Garigliano river valley has a simple, flat layered geometry; away from the valley edges, a 1-D model of layers over a half space may be adequate to predict the transfer function.

\section{OBSERVED SITE RESPONSE}

The Garigliano river valley is characterized by a significant amplification of seismic waves. Rovelli et al. (1988) estimated this amplification from two strong-motion accelerograms recorded in the valley, less than $1 \mathrm{~km}$ apart from our array site. The first was recorded during the 23 November 1980 Irpinia earthquake; the second during the 7 May 1984 Lazio-Abruzzo earthquake. Unfortunately, no recordings of these events were available on close hard-rock 


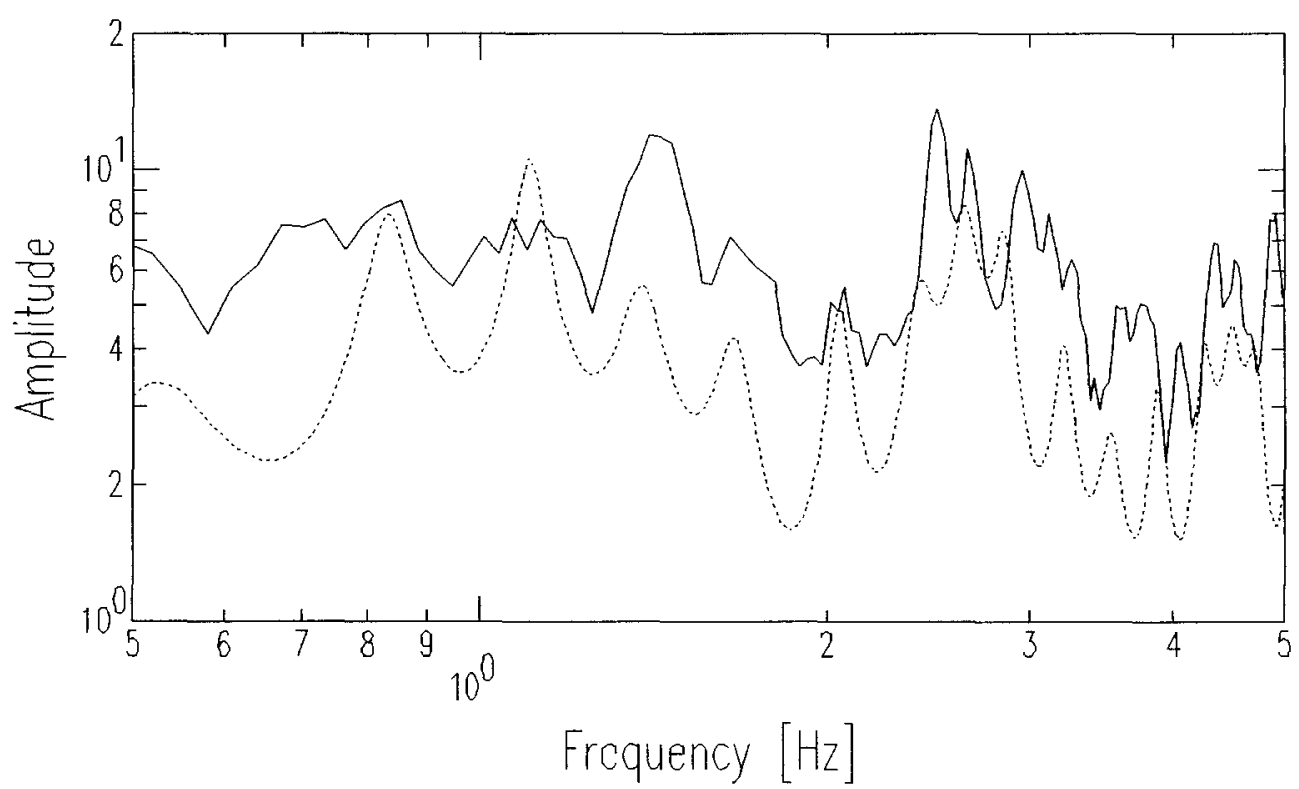

FIG. 5. The inferred velocity model (Fig. 4) is used to compute theoretical 1-D transfer functions (dashed line). Also shown (solid line) is the averaged spectral ratio obtained from weak motions recorded at GRG and CNO.

reference sites. We deployed a pair of three-component kinemetrics 5-sec sensors in the middle of the Garigliano river valley $\approx 100 \mathrm{~m}$ from the array center, and at a hard-rock reference site. These sites are indicated as GRG and CNO in Figure 1b. The aim was to record local and regional earthquakes for the quantification of site response (see Fig. 1). Over a 5 mo-long deployment, we recorded three events with adequate signal-to-noise ratios at both sites (see Table 1). One of these events is the $m_{b}=4.6$ Potenza earthquake of 5 May 1991. Its focal mechanism is shown in Figure 1.

To compute spectral ratios, we calculate Fourier spectra for 30 -sec windows bracketing the highest amplitude $L g$ arrivals. The time series are tapered over $\pm 5 \%$ and the spectra are computed using a standard FFT. The spectra are smoothed over a $0.3 \mathrm{~Hz}$ bandwidth before the ratio computation. When the significant signal is shorter than $30 \mathrm{sec}$, the selected wavetrain is tapered first, then zeroes are added at the end of the window, before calculating the spectrum.

Spectral ratio estimates are known to be plagued by large uncertainties (Field et al., 1992). One way to reduce these uncertainties in the estimation of site

TABLE 1

Events UsEd IN THIS STUdy

\begin{tabular}{|c|c|c|c|}
\hline Event & Date & Magnitude & Location \\
\hline Potenza & 26 May 1991 & $M_{L}=4.8$ & $40.7 \mathrm{~N} 15.9 \mathrm{E}$ \\
\hline Albani Hills & 4 July 1991 & $M_{L}^{L}=3.1$ & $41.6 \mathrm{~N} 12.8 \mathrm{E}$ \\
\hline Albani Hills & 12 September 1991 & $M_{L}=2.9$ & $41.6 \mathrm{~N} 12.7 \mathrm{E}$ \\
\hline
\end{tabular}


response is to average spectral ratios obtained at the same pair of stations from numerous earthquakes. When data are scarce, it is desirable to combine all available data, irrespective of azimuth or epicentral distance.

The three earthquakes recorded at our pair of sites come from two different source regions (see Fig. 1): the Albani Hills $(20 \mathrm{~km}$ southeast of Rome; $100 \mathrm{~km}$ northwest of our stations) and the Potenza region (190 km southeast of GRG). The spectral ratios available for GRG/CNO were combined into a single logarithmic average shown in Figure 5 (solid line).

The theoretical 1-D transfer function is compared with the observed spectral ratio in Figure 5; the overall agreement is satisfactory, the 1-D approximation may account for some of the discrepancies that do exist between the two curves. A rather critical issue could be the distance of $15 \mathrm{~km}$ between GRG and CNO, which is significantly larger than the values typically used for estimating site amplification from spectral ratios. CNO was located on an outcrop of the deep Jurassic limestone basement which is below the sediment site. We used a 5-layer model in the numerical computation of the 1-D transfer function in order to account for the known stratigraphy. Within the resolution limits imposed by the size of our earthquake data set, we obtain an observed site response that is acceptably modeled by the theoretical prediction.

\section{CONCLUSIONS}

Strong motion accelerograms of two Appennine earthquakes recorded in the Garigliano river valley, Central Italy, show significant local amplification of ground motion due to the presence of soft Holocene sediments (Rovelli et al. 1988). In this paper we performed a frequency-domain formulation of the spatial autocorrelation method of Aki $(1957,1965)$ to infer a shear velocity profile for the valley from ambient noise recordings, and use it to model the 1-D seismic response of sediments.

We installed a circular array of four seismometric stations on sediments: these measurements showed that ambient noise within the valley is high and dominated by energy near 1 to $2 \mathrm{~Hz}$. A strong dispersion was observed in the frequency band between 0.5 and $8 \mathrm{~Hz}$, suggesting that the ambient noise wavefield in the valley is dominated by surface waves. Assuming that the vertical component of microtremor recordings were representative of Rayleighwave motions, we interpreted the dispersion curve in terms of a layered shear-wave velocity structure. We used the method of Takeuchi and Saito (1972) to predict the Rayleigh-wave dispersion curve generated by a laterally homogeneous velocity model. Geological and stratigraphic informations were available to constrain the model, and a trial-and-error approach was used to reduce the misfit between theoretical and empirical data.

A theoretical transfer function was computed from the final velocity model and successively compared with an average spectral ratio obtained from earthquake weak motions recorded by a pair of stations, one in the valley and the other on a hard-rock reference site. The comparison showed a satisfactory agreement.

In light of the noted limitations of the ambient noise methods, the results of this paper suggest that they are mostly useful when applied in conjunction with theoretical predictions of site response, particularly in areas of rare seismicity. Critical to theoretical estimations of site response is information about the subsurface velocity structure. The spatial correlation method of Aki (1957) can 
thus provide a cost-effective way to estimate values of shear-wave velocities in sediment layers.

\section{ACKNOWLEDGMENTS}

This work was conducted with internal research funds of the Istituto Nazionale di Geofisica, and with grants NSF-International 89-16030, NCEER 87-1302 and 88-1302. NCEER is partially supported by the National Science Foundation under grant ECE86-07591. Lamont-Doherty Earth Observatory contribution 5133 .

The authors wish to thank personnel from ENEL, Direzione delle Costruzioni, for allowing access and measurements in reserved areas. Particular thanks are due to Raniero Berardi for discussions concerning stratigraphy at the site of the ENEL accelerometric station of Garigliano.

\section{REFERENCES}

Aki, K. (1957). Space and time spectra of stationary stochastic waves with special reference to microtremors, Bull. Earthquake Res. Inst. Tokyo Univ. 35, 415-457.

Aki, K. (1965). A note on the use of microseisms in determining the shallow structure of the Earth's crust, Geophysics 30, 665-666.

Bard, P. Y. and M. Bouchon (1985). The two-dimensional resonance of sediment-filled valleys, Bull. Seism. Soc. Am. 75, 519-540.

Borcherdt, R. D. (1970). Effects of local geology on ground motion near San Francisco Bay, Bull. Seism. Soc. Am. 60, 29-61.

Bracewell, R. N. (1978). The Fourier transform and its applications, McGraw-Hill, New York.

Ferrazzini, V., K. Aki, and B. Chouet (1991). Characteristics of seismic waves composing Hawaiian volcanic tremors and gas-piston events observed by a near source array, J. Geophys. Res. 96, 6199-6209.

Field, E. H., S. E. Hough, and K. H. Jacob (1990). Using microtremors to assess potential earthquake site response: a case study in Flushing Meadows, New York City, Bull. Seism. Soc. Am. 80, $1456-1480$.

Field, E. H., K. H. Jacob, and S. E. Hough (1992). Earthquake site response estimation: a weak-motion case study, Bull, Seism. Soc. Am. 82, 2283-2307.

Frankel, A., S. E. Hough, P. A. Friberg, and R. Busby (1991). Analysis and modeling of waveforms of Loma Prieta aftershocks recorded on a dense array in Sunnyvale, California, Bull. Seism. Soc. Am. 81, 1900-1922.

Gutierrez, C. and S. K. Singh (1992). A site effect study in Acapulco, Guerrero, Mexico: comparison of results from strong-motion and microtremor data, Bull. Seism. Soc. Am. 82, 642-659.

Henstridge, J. D. (1979). A signal processing method for circular arrays, Geophysics 44, 179-184.

Hough, S. E. (1990). Constraining sediment thickness in the San Francisco Bay area using observed resonances and $P$-to-S conversions, Geophys. Res. Lett. 17, 1469-1473.

Hough, S. E., L. Seeber, A. Rovelli, L. Malagnini, A. De Cesare, G. Selvaggi, and A. Lerner-Lam (1992). Ambient noise and weak-motion excitation of sediment resonances: results from the Tiber Valley, Italy, Bull. Seism. Soc. Am. 82, 1186-1205.

Kennett, B. L. N. and N. J. Kerry (1979). Seismic waves in a stratified half space, Geophys. J. R. Astr. Soc. 57, 557-583.

Lermo, J., M. Rodriguez, and S. K. Singh (1988). The Mexico earthquake of September 9, 1985-Natural periods of sites in the Valley of Mexico from microtremor measurements and from strong-motion data, Earthquake Spectra 4, 805-814.

Ohta, Y. H., Kagami, N. Goto, and K. Kudo (1978). Observation of 1- to 5-second microtremors and their application to earthquake engineering. Part I. Comparison with long-period accelerations at the Tokachi-Oki earthquake of 1968, Bull. Seism. Soc. Am. 68, 767-779.

Rovelli, A., O. Bonamassa, M. Cocco, M. Di Bona, and S. Mazza (1988). Scaling laws and spectral parameters of the ground motion in active extensional areas in Italy, Bull. Seism. Soc. Am.78, $530-560$.

Rovelli, A., S. K. Singh, L. Malagnini, A. Amato, and M. Cocco (1991). Feasibility of the use of microtremors in estimating site response during earthquakes: some test cases in Italy, Earthquake Spectra 7, 551-561.

Schuster, G. T., K. Sikorski, and C. Tsay (1988). Simulation of three-dimensional elastic wave propagation in Salt Lake Basin models by a parallel computer (abstract), EOS 60, 1334. 
Takeuchi, Y. and M. Saito (1972). Seismic surface waves, in "Seismology. Surface Waves and Earth Oscillations," B. A. Bolt (Editor), Academic Press, New York.

Udwadia, F. E. and M. D. Trifunac (1973). Comparison of earthquake and microtremor ground motions in El Centro, California, Bull. Seism. Soc. Am. 63, 1227-1253.

Istituto Nazionale di GEOFisica

VIa di Vigna Murata 605

00143 ROMA, ITALY

(L.M., A.R.)

Manuscript received 17 November 1992
LAMONT-DOHERTY EARTH OBSERVATORY Columbia University

Palisades, New York 10964

(S.E.H., L.S.) 